\title{
Field Metaphysic, Power, and Individuation in Spinoza
}

\author{
VALTTERI VILJANEN \\ University of Turku \\ 20014 Turku \\ Finland
}

\section{Introduction}

Spinoza developed a highly interesting metaphysical theory of nature and individuality. In this paper, I endeavor to bring forward some ideas on how Spinozistic views on extended substance, physical world, and individuality can be approached using the concept of power as the basis of interpretation. Jonathan Bennett's 'field metaphysical' interpretation of Spinoza's doctrine of one extended substance has generated much discussion, and forms the other starting point of my paper. I believe that the field metaphysical interpretation enables one to deal with the central questions concerning physical individuation - individuality and the persistence of individual being - in a rather novel way. My main question is this: what follows if physical individuals are seen as parts of a unified field of extended power?

I will begin by presenting some general features of my interpretation of Spinozistic substance and finite things as power. After these remarks concerning the basis of Spinozistic thought, I will expound the philosophical problems Bennett's field metaphysical interpretation solves and show how his position can be combined with the view that takes the ontological principle of power as the point of departure in interpreting Spinoza's thought. Following this discussion of Spinozistic ontology, I will offer an analysis of the relation between the metaphysical and physical points of view in the Ethics. Lastly, I shall explicate how 
the question concerning finite individuals' persistence can be answered from my position. I will argue that when interpreted using power as the key concept, Spinoza's theory of extended substance and individuality appears not only quite coherent and intelligible, but also much more exciting than has often been thought; indeed, keeping in view how important the idea of describing human existence in dynamic terms is for our philosophical heritage (one must only consider such thinkers as Leibniz, Schopenhauer, and Nietzsche), these aspects of Spinozism merit our serious attention.

\section{Substance and finite things as power}

As is well known, Spinoza argues in the first part of the Ethics that there is only one substance, namely God (E1p14), ${ }^{1}$ and that this substance exists necessarily (E1p11). His argument for the necessity of God's existence has been much debated, and its analysis is beyond the scope of this paper. Instead, I would like to turn to the question concerning God's nature, for it should be asked what kind of being this necessarily existing God could be. That is, how can we describe more positively the being that is the cause of itself? The crucial characterization can be found in E1p34: 'God's power [potentia] is his essence itself.' ${ }^{2}$ This can be seen as the cornerstone of Spinozistic dynamism, in which the nature of the necessarily existing God is power. Spinoza need not be seen here as guilty of some kind of obscurantism in the sense of presenting an occult quality of power he should rather be trying to eliminate. Instead, we should take a look at his reasons for E1p34 from that proposition's demonstration: 'For from the necessity alone of God's essence it follows that God is the cause of himself (by p11) and (by p16 and

1 I have used the following method in referring to the Ethics: a = axiom, app = appendix, $c=$ corollary, $d=$ definition (when not after a proposition number), $d=$ demonstration (when after a proposition number), le $=$ lemma, $p=$ proposition, pref $=$ preface, $s=$ scholium. For instance, E1p8s2 refers to the second scholium of the eighth proposition in the first part of the Ethics.

2 E1d6, '[b]y God I understand a being absolutely infinite, i.e., a substance consisting of infinity of attributes, of which each one expresses an eternal and infinite essence,' expresses, of course, Spinoza's fundamental view on God's nature. However, he speaks about God's essence as power, too, and my aim here is to examine the implications of that identification and its connection to E1d6. Spinoza identifies God's power and essence already in Descartes' 'Principles of Philosophy' where he notes, after using them interchangeably, that 'the power by which the substance preserves itself is nothing but its essence, and differs from it only in name' (DPP1p7s). 
p16c) of all things.' In other words, Spinoza claims that since - as the crucial E1p16 states - things are what they are and the way they are because everything there is follows, with geometrical necessity, from God's essence, this essence is to be identified with power. Now, what is the rationale behind this? I would suggest that the identification of essence and power has to do with the fact that from E1p16 onwards Spinoza discusses the nature of causality, and he clearly finds 'power' to be a suitable term for characterizing it; talk about causality can be, as it were, translated into talk about power. To be able to cause effects is to be powerful, and therefore the all-causing God's essence equals power. The connection between the interrelated concepts of essence, causality, and power can be summed up by saying that, in general in the Ethics, power means being able to cause effects, and since things cause effects in virtue of their essences (see e.g. E1p16, 1p36, 3p7, d), essences are intrinsically powerful. The basic case of God is, of course, the most important one, for God's essence is ultimately responsible for everything there is. And as attributes constitute it (E1d4, 1d6), it is understandable that, for Spinoza, they cannot be inert like Cartesian extension is; instead, they are capable of producing all the modifications falling under them. That is probably why Spinoza writes in his correspondence that 'from Extension as conceived by Descartes, to wit, an inert mass, it is not only difficult ... but quite impossible to demonstrate the existence of bodies.' (Ep81) 3 The concept of power evokes this dynamistic aspect of the Spinozistic attributes and what may be called the essentialist model of causal activity on which the system is built. ${ }^{4}$

Spinoza's thinking in E1p34 can be seen as an instance of his explanatory rationalism: there must be an ultimate explanation for being in general and for being of each thing in particular (see E1p11d). Concerning the issues discussed thus far, this line of thinking leads, to my lights at least, Spinoza to the idea that everything possible is necessary, and the realization of these possibilities requires power. Consequently, all existence has what may be called substantial power of existing as its basis. ${ }^{5}$ This interpretation finds support from E1p11, especially from its second alternative demonstration, where Spinoza states that 'to be able to exist is to have power.' Also in E1p11s, Spinoza claims that 'an

3 For more on Ep81 and 83, see below.

4 In this he is, in part, following the tradition: as Wolfson (1961 [1934], I, 403, 405) explains, the Medievals characterized God's causality by three attributes: intellect, will, and power. But in the Ethics only power is identified with essence, whereas intellect and will are merely modes of substance.

5 See also Pietarinen, 2000a, 196; 2000b, 67; 2003, 141. 
absolutely infinite Being, or God, has, of himself, an absolutely infinite power of existing.' This means that in Spinozistic ontology power plays a key role, grounding all being: accordingly, Spinoza identifies reality, power, and perfection with each other (see E1p11s, 2d6).

As far as finite beings are concerned, Spinoza states in E1p34d what follows from this fundamental power of the only substance: all things are and act by the power of God. Finite beings are modes or affections of substance - that is, expressions of God's attributes (E1p25c) - and hence expressions of substantial power under different attributes. This means that each singular thing is a part of God's infinite power (E4p4d) and expresses this power of God in a certain and determinate way (E3p6d). As Margaret Wilson remarks, it is important to make the often overlooked distinction between modal existence purely as essence ('in the attributes of $\mathrm{God}^{\prime}$ ) and modal existence in time and place ('under duration,' that is, 'actually'). ${ }^{6}$ A thing's portion of God's power is its essence (E3p6d, 3p7), and essences exist eternally, atemporally, in God (see E2p8, 5p22, 5p23).

However, although substantial power is the efficient cause of the essence of a singular thing (E1p25), the reason for temporal existence of any finite mode cannot be its essence (E1p24): Spinoza claims that finite modes can become actual only through the effects of other actual finite modes (E1p28). This means that the beginning of the actual being of a mode depends on the infinite totality of modes - that is, the chain of causes and effects that continues without end - and not on the eternal essence of the mode.

I believe that the concept of power must be taken seriously in order to understand the overall construction of Spinoza's philosophy. His philosophy of power is particularly strongly at work in the third and fourth parts of the Ethics, where he deals with temporal individual existence: emotions and our basic nature are defined in terms of power (E3d3, 3p6, $3 p 7)$. In connection with this, it should be kept in mind that the question of motion and its persistence forms an important part of the background for seventeenth century philosophy. Descartes, Hobbes, Spinoza, and Leibniz all wanted to explain philosophically the new law of motion asserting that if a body moves, it will continue to move unless it is affected by external causes. Seen in this context, Spinozistic metaphysics of power is one answer to the essential problem of motion. However, this brief outline of substance and finite things must suffice for my present concerns, and I will now move on to analyzing its implications for Spinoza's theory of substance under the attribute of extension. 


\section{Field metaphysic of power}

\section{Bennett's field metaphysical interpretation of extended substance}

Bennett presented his groundbreaking field metaphysical interpretation of extended substance in A Study of Spinoza's Ethics, published in 1984. Although similar views of Spinoza's metaphysics had been expressed earlier, Bennett was the first to give this line of thought a philosophically elaborated form. ${ }^{7}$ After expounding his interpretation I will examine it in connection with the idea of substantial power.

Bennett calls substance expressed under the attribute of extension, or the one extended substance, space. As he explains, the need for partless substances stems from the seventeenth-century view that substances must be causally and conceptually independent. If a substance consisted of (substantial) parts, it would be ontologically dependent on those parts, and therefore would no longer be a substance. This requirement creates difficulties especially in the case of extended substances, since it was commonly held that every physical object is always divisible into separate parts. ${ }^{8}$ On the other hand, as Martial Gueroult notes, infinite extension and divisibility were traditionally thought to exclude each other, and the idea of infinite extension was rejected. But this was not Spinoza's approach; he holds on to infinity and rejects divisibility. ${ }^{9}$ What Bennett calls 'field metaphysic' should be seen as a solution to the problems pertaining to the monistic idea of extension as substance: if there really is only a single extended, ontologically independent and unified substance, how should we understand the basic nature of all the divergent physical entities we are familiar with? How to explicate the relation between physical bodies and space as a whole? This is precisely the problem addressed in the very important E1p15s. Spinoza makes there a distinction between two ways of conceiving extended nature. He claims that those who are inclined to divide extension attend to it only superficially, as it appears to our senses, and consequently find it to be composed of parts. But if the intellect attends to extended nature as a substance, Spinoza insists that 'it will be found to be infinite, unique,

7 For texts at least suggesting a field metaphysical interpretation of Spinozistic extension, see Harris, 1973, 50-6, 65, 68-9; Lachterman, 1978, 103; Sachs, 1976, 130-1; Van Zandt, 1986, 255-60; von Dunin Borkowski, 1933, 97-101; Wolf, 1974 (1927), 214. For a discussion of Spinozism and Bennett's interpretation as space-holism, see Esfeld, 2002, 213-38. For a recent attempt to combine Spinozistic field metaphysic with Kantian transcendental philosophy, see Rohs, 1996.

8 Bennett, 1984, 82-3; see also Bennett, 1996, 62-3.

9 Gueroult, 1968, 214-15 
and indivisible' (E1p15s). Thus Spinozistic space is a unity: it cannot be divided in the sense of having really distinct parts. According to Bennett, Spinoza can defend this idea of unified space, not constituted by its parts, in the following way:

[T]he thought of a whole space is not built up out of thoughts of its subregions, whereas the thought of any finite region of space must involve the thought of a larger region - or the whole of space - within which it is embedded. ... [T] he very concept of spatial region involves the concept of the space of which it is a region. ${ }^{10}$

In other words, no part of space can exist, or be understood, without relation to the space as a whole, and hence its parts cannot be really distinct from each other. Obviously, this tells us something decisive about the meaning of Spinoza's assertion that 'nothing can be or be conceived without God' of E1p15.

So if unified space is the only substantial extended entity there is, what should we say about finite things? Here, of course, the doctrine of substance and its modes comes to the fore. As mentioned above, for Spinoza finite things are modes, that is, affections or states of substance that can neither be, nor be conceived, apart from substance. Consequently, although extended substance cannot strictly speaking be divided, it is not altogether without distinctions:

[M]atter is everywhere the same, and ... parts are distinguished in it only insofar as we conceive matter to be affected in different ways, so that its parts are distinguished only modally, but not really. (E1p15s)

In other words, the variety of material phenomena results from the one substance being affected in infinitely many ways. As has been frequently pointed out, not having substantially distinct parts does not prevent substance from having modally distinct parts. But what does it mean to be 'modally distinguished,' or 'an affection of substance'? This question can be answered by the field metaphysical account: the regions of the whole space can become many different kinds of qualities in such a way that statements about material bodies can be reduced to statements about space. ${ }^{11}$ More exactly, each particular body must be

10 Bennett, 1984, 86

11 It should be noted that despite talking, for practical reasons, about spatial regions, Bennett $(2001,143)$ consistently stresses that 'regions depend for their existence on the existence of Space as a whole;' accordingly, he is not guilty of treating regions of space as basic things. Moreover, he does not quantify over them: by using adjectives and adverbs the field metaphysical account can be given without mentioning 
associated with a spatio-temporally continuous string of place-times. The central idea is that bodily objects must be logical constructions out of strings of place-times, for Spinoza's basic ontology does not contain physical objects. According to Bennett, this makes bodies adjectival to regions of space; all the statements about bodies can at least in principle be expressed in terms of "how Space is. ${ }^{12}$

As a result it follows that what we see as a distinct material thing, for example as a chair, is more adequately conceived as a certain spatial region being 'chairy*', that is, having that modal property of space which we conceptualize at the physical level - 'one level up' from the field metaphysical one - as a chair. Moreover, Bennett claims that what we would ordinarily call movement of a body is not literally speaking movement, but simply an alteration in which spatial regions have the property we conceptualize as the body. ${ }^{13}$ For example, if we move a chair, there is a continuous change in which spatial regions are chairy*. Or as Bennett himself puts it, 'Spinoza's view is that the movement of things or stuff is, deep down, the passing along of something qualitative - a change in which regions are $\mathrm{F}$ and which are not, for suitable values of $\mathrm{F}^{\prime 14}$ Since metaphysically speaking there is only one 'thing,' the whole extended world, there cannot be moving bodies, either; consequently, Bennett holds that motion ordinarily understood does not belong to Spinozistic ontology. ${ }^{15}$

According to this kind of field metaphysic, the destruction of a finite individual does not amount to the annihilation of a certain region of extended substance, but only to spatial alteration. This is in complete agreement with the following important passage of the Ethics:

For example, we conceive that water is divided and its parts separated from one another - insofar as it is water, but not insofar as it is corporeal substance. For insofar as it is substance, it is neither separated nor divided. Again, water, insofar

regions (Bennett, 1984, 95; 2001, 143). Nevertheless, Bennett (1984, 95-6; 1991, 55-6) is probably right in holding that a complete account of the world must involve indexical adverbs such as 'here' and 'there,' for otherwise genuine reference to particulars becomes impossible, and it certainly seems hard to find room for indexicality in Spinoza's system. However, because any interpretation of Spinoza's monism must face the problem of indexicality, it poses no particular threat to the field metaphysical interpretation.

12 Bennett, 1984, 89, 92, 95-6; 2001, 143-4

13 Bennett, 1984, 96, 106-7; 1996, 71

14 Bennett, 1984, 89-90

15 Bennett, 2001, 143, 148; 1984, 90, 106 
as it is water, is generated and corrupted, but insofar as it is substance, it is neither generated nor corrupted. (E1p15s)

In other words, despite the fact that material things can be driven out of existence, space itself cannot be annihilated. Furthermore, as Bennett points out, a rather perplexing statement in letter 4 makes sense from the field metaphysical point of view: '[I]f one part of matter were to be annihilated, the whole of Extension would also vanish at the same time' (Ep4). ${ }^{16}$ That is, if extended substance as space forms one unified field, then annihilation of one part of it would amount to the total annihilation of the whole field - and hence there can be no vacuum in the sense that a part of space would cease to exist. ${ }^{17}$ This is not what happens when bodies go out of existence. In Bennett's terms, for example a chair's destruction means that a region ceases to be chairy* and no adjoining region becomes chairy*. Briefly said, 'nothing goes out of existence, but something alters. ${ }^{18}$

\section{Field metaphysic and substantial power}

As one would expect, Bennett's field metaphysical interpretation has had its share of criticism as well. Most notable is the one presented by Edwin Curley. After finding Bennett's account of the relation between field metaphysical and physical level unconvincing, Curley sums up his sentiments in a direct manner: 'In this respect Bennett seems to me to be engaging in speculative reinterpretation rather than in interpretation. ${ }^{, 19}$ It is true that Bennett's view is in many ways radical, but before writing it off as simply anachronistic one should think over how well it handles the texts presented above, some of the trickiest passages Spinoza ever wrote. Moreover, there is a genuine philosophical problem - namely,

16 Bennett $(1984,98)$ claims that apart from his interpretation, he cannot find any other basis on which this piece of text would be 'even sane.' However, for another interpretation of it that does not strike me as outright unintelligible, see Gueroult, 1968, 216.

17 Bennett, 1984, 97-102. In other words, from the Spinozistic point of view 'vacuum' is a nonsense term, an 'extended nothing' (Bennett, 1984, 100). Cf. Lecrivain, 1986, $37-8$.

18 Bennett, 1996, 71

19 Curley, 1991, 44. It should be noted that Bennett (1991, 56-7; 2001, 147-8) answers this criticism by arguing very convincingly about the nature of metaphysics and its difference to physics. Although Spinoza's physics is about matter in motion, this does not mean that his metaphysics could not be about something fundamentally different (and I think that it certainly is). 
how should the character of finite physical entities be understood in substance monism that applies to extension - that can be answered by interpreting Spinoza the way Bennett does. ${ }^{20}$ Indeed, it seems obvious to me that Spinoza's thinking about these matters remained relatively stable at least since the early Short Treatise. Consider the following passages: '[N]o parts of it [extension] could be understood separately.' (KV I.ii, § 19.2) '[D]ivision never occurs in the substance, but always and only in the modes of the substance. So if I divide water, I divide only the mode of the substance, not the substance itself.' (KV I.ii, § 21) '[W]hen we say that a man perishes, or is destroyed, that is only understood of the man insofar as he is a composite thing and mode of substance, and not the substance itself on which he depends.' (KV I.ii, § 22) These passages show that Spinoza thought long and hard about issues related to field metaphysic.

Bennett notes that field metaphysic does not necessarily lead to physics of material particles, and he suggests that the best way to understand what is meant by 'an occupant of space' might be to replace the concept of a physical thing with the concept of a force or a wave. ${ }^{21}$ True as this is, I think the question can also be posed the other way round: instead of asking what kind of physics can be combined with field metaphysic, it can be asked what kind of view of the basic nature of substance can be combined with the field metaphysical character of extension. Consequently, I want to take essential substantial power as the starting point and see how well it fares in connection with field metaphysic. Although Bennett admits that it is important for Spinoza to see 'the world as somehow self-moving, perhaps like an animal,' he does not develop this theme any further, since he cannot 'make it yield interesting philosophy. ${ }^{, 22}$ Generally speaking, the concept of power does not occupy an important position in Bennett's studies of Spinoza.

I would like to further elaborate on Bennett's account by moving to a more dynamic frame of mind in which substance is regarded as substantial power realizing the necessitarianism Spinoza's system implies. It should be noticed that many French Spinoza scholars have under-

20 Bennett $(1991,54-5 ; 2001,145-6)$ points out that he and Curley probably differ in their general view of what kind of thinker Spinoza is - Bennett picturing him as bolder and more reckless than Curley does. This claim holds water, but is no argument for the field metaphysical interpretation, not the least because the boldness and originality of Spinoza as a thinker is largely determined by what kind of overall interpretation of his metaphysical writings one accepts.

21 Bennett, 1984, 106

22 Bennett, 1984, 107. Interestingly enough, at one point Gueroult $(1974,177)$ claims that in Spinozistic material universe everything is 'animal-machine.' 
stood this active nature of substance. Just to name a couple of more classic writers: according to Matheron, extension is pure spatial activity that produces the modes; ${ }^{23}$ Deleuze calls substance absolutely infinite power of existing in all forms; ${ }^{24}$ and Gueroult concludes that for Spinoza extension is not inert mass, but an attribute that has power both of self-production and of production of modes. ${ }^{25}$

When this notion of extension as a form of substantial power is combined with Bennett's view of extension as unified field of space, it can be seen that they fit very nicely together. The result is the idea of space as one unified field of spatial power. Thus, seen from the dynamic point of view, extended power forms a spatial continuum with no autonomous, really distinct parts. Substantial power is a fundamental unity, and consequently, in ontological terms it is not correct to refer to finite entities without relating them to the whole substantial power, without seeing them as parts of one power (cf. E4p4d). I want to stress that I accept the core of the above discussed field metaphysical thesis: space can be modified in many ways and from this result the innumerable phenomena of the physical world. However, what is essential to my approach is to pose the question concerning extended substance and modes in terms of power and its states. What kind of states or affections could there be in spatial power? Now, it is fundamentally right to hold that the relationship between substance and modes is not merely one of causal dependence in the sense that modes are produced by substance, but also one of inherence in the sense that modes exist in substance. ${ }^{26}$ Here the metaphor of sea and its waves is, to my mind, enlightening: as waves cannot exist other than as parts of a sea, the sea is always wavy in a certain way, in some wave state; and each idea of a wave involves an idea of the sea, just as any idea of a physical thing involves the idea of extension. Further, substance as power is no static thing, and consequently its affections should not be seen in the mold of properties of everyday things. Since modally distinguished parts constitute differing amounts of God's power, I suggest that under the attribute of extension we are dealing with differences in power distribution in the spatial field: finite entities are, field metaphysically speaking, constituted by differences in the intensity or strength of spatial power. These distributive differences in intensity form relatively stable spatial patterns 
or formations, i.e. modes of extension. This is what it means for them to be parts of substantial power. ${ }^{27}$ There is no region without power, since that would equal total annihilation of extension, but there are drastic differences in the intensity of power between spatial regions, and out of these differences finite things are constituted.

Hence, the material bodies we encounter in the physical world are ontologically speaking modifications of spatial power; seen from the metaphysical standpoint there are only spatially distributed alterations in power. Consequently, motion and change of a physical body are alterations in the one extended field of power - alterations in which regions carry such a pattern of intensity that a certain material body is thereby constituted. And following Bennett's analysis, a finite mode's destruction cannot mean annihilation of power, but only such an alteration in it that no region carries anymore the formation of intensity that equals the mode ontologically described. Hence, claims about material bodies are, deep down, not just claims about space, but claims about spatially distributed intensities of power.

To back up my claims I would like to bring forward some textual evidence, some of which I mentioned already in the beginning of this paper. Spinoza's dynamic conception of space can be found in the following passage that has sometimes been considered to be quite cryptic: $^{28}$

[F]rom Extension as conceived by Descartes, to wit, an inert mass, it is not only difficult ... but quite impossible to demonstrate the existence of bodies. For matter at rest, as far as in it lies, will continue to be at rest, and will not be set in motion except by a more powerful external cause. For this reason I have not hesitated on a previous occasion to affirm that Descartes' principles of natural things are of no service, not to say quite wrong. (Ep81)

Still more important is the highly exciting passage included in the next letter he sent to Tschirnhaus:

With regard to your question as to whether the variety of things can be demonstrated a priori solely from the conception of Extension, I think I have already made it clear that this is impossible. That is why Descartes is wrong in defining matter through Extension; it must necessarily be explicated through an attribute which expresses eternal and infinite essence. (Ep83; emphasis added)

27 Cf. Deleuze (1997 [1968], 227), 'the very idea of the mode is ... the only way showing how things "participate" in God's power, that is, how they are parts of divine power.' 
I think that these passages strongly point to the direction of my interpretation. To be more exact, two central points can be extracted from them: firstly, extension should not be thought of as inert mass (Ep81); secondly, matter cannot be derived from the concept of extension alone, but follows from an attribute which expresses God's essence (Ep83), i.e. his power (E1p34). Letter 83 especially challenges many traditional interpretations of matter, extension, and substance in Spinoza's ontology. And saying that matter cannot be defined solely through extension speaks against Bennett's position, according to which the concept of mass should be constructed out of properties of spatial regions ${ }^{29}-$ i.e. from properties of the one extended substance. Yet letter 83 explicitly denies this kind of 'defining matter through Extension.' Spinoza seems to imply that something more fundamental than matter or extension is involved here, and my claim is that he is pointing precisely to the nature of substance as active power; this is what Spinoza means when speaks (in his idiom) of matter being 'explicated through an attribute which expresses eternal and infinite essence' (Ep83). The point is that since extension (as an attribute) expresses God's essence or power, matter should be understood through a dynamic conception of extension, that is, through active extension that needs nothing external to itself to generate the variety of corporeal things. ${ }^{30}$ This kind of extension can be said to have an internal principle of change $;^{31}$ it is not a realm of inert entities but a whole in which intrinsically striving entities - one could say strivers of different sorts - endeavor to occupy regions of extension. And these internally produced strivings lead to changes in the extended world. ${ }^{32}$

So, I hold that in Spinoza's monism spatial patterns of intensity produce the variety we experience as material things and their properties. ${ }^{33}$

Bennett, 1984, 90

30 For an enlightening recent discussion of these letters that agrees with mine, see Della Rocca, 2003, 225-6. For an informative account of the important concept of expression, see Deleuze, 1997 (1968), 13-22, 169-86.

31 For this formulation I am grateful to an anonymous referee of this journal.

32 For more on the doctrine of striving (conatus), see below.

33 Bennett $(1984,89)$ and Olli Koistinen $(1991,51)$ suggest that physical things are regions of space suitably thickened. I do not think their position is totally unlike mine, for gradations of intensity in the field of power can be seen as resulting in material objects as 'thickenings' of extension. However, Bennett (1984, 93-4) thinks that individual things are properties of God and as such honest universals, whereas Koistinen $(1991,80-1)$ holds that they are particular states of God, that is, exemplifications of properties by God and hence entities that consist both of substance and a property. 
Moreover, seeing modes as gradually differing intensities explains why Spinoza clearly thinks of reality and existence quantitatively: a thing can be more or less real and perfect, have more or less being and power (see E1p9, 1p11d, 1p11s). In other words, instead of understanding existence as either-or, Spinoza thinks of it in the axis of more-less. ${ }^{34}$ Bennett, however, sees a problem in the status of motion in Spinoza's system. Spinoza thinks that motion and rest generate the variety in the physical world (E2p13le1), 'motion and rest' being the immediate infinite mode of extension (Ep64), but since according to Bennett's field metaphysical position no thing moves, there is no 'movement literally so-called' in the spatial field at all. ${ }^{35}$ Thus it would seem rather unclear what we should make of motion (and rest) from the field metaphysical point of view. However, I think that this difficulty is quite solvable: there is nothing problematic about spatial field of power being divided or patterned in regard to motion and rest - since patterns of intensifications are extended they can occupy varying regions of spatial field, i.e., they can move. To think of motion as intensifications filling different regions in the space-field at different times may be unlike our everyday conception of motion, but we are still here dealing with motion, only this time motion field metaphysically described. This way interpreted, 'motion and rest' refers to the fact that the spatio-temporal field undergoes changes ceaselessly, for the substantial power is continually redistributed between regions of space. What is more, arrangement, re-arrangement, and motion of spatial intensifications of power necessarily obey the laws of God's essence, as the assertion 'since the nature of the universe ... is absolutely infinite, its parts are controlled by the nature of this infinite power in infinite ways, and are compelled to undergo infinite variations' (Ep32; translation modified, emphasis added) makes clear.

To summarize: Bennett succeeds in giving an insightful account of an important aspect of extended substance, namely its unified field character. However, it does not follow from this that field metaphysic would be all there is to say about Spinozistic substance. Although field

34 It may not be totally uninteresting to note that Bennett $(1984,104)$ ponders whether Spinoza's 'metaphysic takes "substance" not to be a count noun like "pebble" but rather a mass noun like "water".' However, both of these options are nouns, whereas I would rather characterize substance as a verb - substance acts, exists, produces, maintains, and so on. This way substance can be seen as the fundamental principle of acting, existing, persevering, etc. My point is that the notion of substance is far too easily conceived in terms of an inert thing, and in Spinoza's case we should avoid doing this. 
metaphysic in itself does not necessarily lead to the idea of substantial power, I argue that starting from Spinoza's premises substance can be quite naturally seen as a field of activity, and the fact that the field metaphysical interpretation can be quite seamlessly combined with the dynamistic aspects of Spinoza's thought gives additional support to it. Moreover, as Bennett holds, field metaphysical interpretation of substance monism is certainly not without its merits: besides showing how the overall relation between extended substance and finite bodies should be adequately conceived, it provides solutions to such troublesome philosophical problems as corporeal annihilation and co-location of bodies. ${ }^{36}$ But it is preferable to see the field as a field of intensification patterns, not of some other kind of properties, for they are not only compatible with Bennett's analysis of motion but, most importantly, in line with Spinoza's dynamistic tendencies, and this provides us a view of extension as a field where modifications resist and aid each other in their striving to occupy spatial regions.

My interpretation rests on the contention that Spinoza's central aim was to give solid metaphysical moorings to the new mechanistic physics, for this is the only way the most important question of our ethical position in the post-Aristotelian world can be justifiably answered: '[T]he Ethics ... must be based on metaphysics and physics' (Ep27). And I side with Bennett in holding that Spinoza was indeed deeply innovative, profound, and bold in dealing with these hard fundamental questions. However, it is likely that Spinoza did not succeed in every respect in presenting his metaphysical views in as thorough manner as he would have preferred. For example, the letter to Tschirnhaus discussed above shows that after denying that matter could be defined through extension, and claiming that it must be 'explicated through an attribute which expresses eternal and infinite essence,' he adds that 'perhaps, if I live long enough, I shall some time discuss this view with you more clearly; for as yet I have not had the opportunity to arrange in due order anything on this subject' (Ep83). Only seven months later he was already dead, and the exposition presenting 'in due order' these demanding matters was never written. Nevertheless, the basic ontological principle of active power, which is expressed in different forms, can be seen clearly enough at work in the Ethics and makes it possible to disclose what he had in mind.

As mentioned above, field metaphysical interpretation of Spinozistic ontology does not necessarily entail physics of matter in motion, but I shall argue that Spinoza's physics is nevertheless in consonance with 
the field metaphysic of power, and can even give support to it. Indeed, I want to show that one of the main strengths of the viewpoint of power is how well it allows us to deal with Spinoza's physics and theory of individuation, providing us with a fresh perspective to his theory of individuality.

\section{Field metaphysic and physical individuality}

The 'Physical Digression' of the second part of the Ethics (inserted between E2p13 and p14) is the unquestionable basis of Spinozistic physics of matter in motion. Spinoza presents in it a compelling theory of individuation for a class of physical beings he calls 'individuals,' and thus it tells us the story of what he takes corporeal things of the physical world to be. Hence, it should be read with care. At this point it should be emphasized that Bennett's talk of 'Spinoza's two levels,' metaphysical and physical, concern two different ways of describing the same thing, namely the attribute of extension - although it should be remembered that, in philosophical terms, the field metaphysical description is the far more adequate one. ${ }^{37}$

The first lemma of the Digression deals with the basic principles of physical existence. Understandably enough, it follows from Spinozistic substance monism that finite entities cannot be distinct substances: 'Bodies are distinguished from one another by reason of motion and rest, speed and slowness, and not by reason of substance' (E2p13le1). Spinoza's claim that bodies are identified on the basis of motion and rest is only one of the instances where the paramount importance of the new concept of motion can be seen. As mentioned above, it provides an inevitable context for his metaphysics. What is important to note here, however, is that Spinoza regards motion and rest as the principle generating the variety of the physical world. He does not think of matter in terms of inert mass, but in terms of motion - which is in consonance with the dynamism of his metaphysics.

To understand Spinoza's thought on physical individuals it is very important to know what he means by a fundamental class of extended entities he calls 'the simplest bodies' (corpora simplicissima), which 'are distinguished from one another only by motion and rest, speed and slowness' (E2p13le3a2d). The doctrine of the simplest bodies is quite puzzling. If they are interpreted as the smallest possible bodies, difficulties arise. For as I have already noted, many philosophers held in 
Spinoza's time that all extended things, regardless of their size, are divisible into smaller parts, and consequently there cannot be so small a body that it could not be further divided. Thus, the concept of 'smallest possible body' is highly problematic. However, I believe that the viewpoint of power can provide a solution to the problem of simplest bodies. Since extension is fundamentally a field of power, and since that field is divided in regard to motion and rest, simplest bodies can be interpreted as basic unvarying alterations of place in the field. ${ }^{38}$ In other words, simplest bodies are, ontologically speaking, rudimentary intensifications of spatial power, or extended power quanta, that invariably change place. ${ }^{39}$ The elementary constituents of the physical world are therefore not lumps of inert mass, but in a constant fashion moving intensifications. I take it that each simplest body has a portion of infinite power belonging exclusively to it, and an extended mode's share of power is determined on the basis of motion and rest. Within this kind of ontological framework, matter is constituted by the interaction of power quanta. The impenetrability of bodies stems from power quanta striving to occupy their region of space, thus preventing other quanta from entering it. ${ }^{40}$

For example, Gueroult and Don Garrett have argued that simplest bodies may be of different sizes. ${ }^{41}$ I agree with them, although I assume that in general simplest bodies must be extremely small. Furthermore, Spinoza was no atomist, and the earlier discussed example of water that can be always divided without any kind of real division in substance (E1p15s; KV I.ii, § 21) makes it quite clear that simplest bodies are not to be understood as indivisible particles. So, each simple body fills its region of space, and even if space were so modified that a simple body would be divided into two halves, the result would be simply

38 I disregard the possibility of simplest bodies at rest for the following reason. Simplest bodies are 'distinguished from one another only by motion and rest, speed and slowness' (E2p13le3a2), and this obviously implies that there could be at most only one simplest body at rest; since this kind of doctrine of the single unmoving simplest body sounds pretty mysterious, I consider it best to think of all the simplest bodies as moving.

39 Pietarinen originally introduced the useful term of power quantum to the context of interpreting Spinoza. However, by the simplest bodies he means the smallest possible quantities of power under the attribute of extension (Pietarinen, 2000a, 197).

40 It is perhaps interesting to note that these views are in many ways similar to those Kant presents in his Physical Monadology (see Kant, 1992 [1756]).

41 Garrett, 1994, 81-2; Gueroult, 1974, 161, 163 
two smaller regions of the same constant motion. ${ }^{42}$ Spinoza's point is to describe the most rudimentary level of the distribution of motion and rest, not to support any kind of atomism.

Just after considering the simplest bodies, Spinoza gives us the definition of 'individual':

When a number of bodies, whether of the same or of different size, are so constrained by other bodies that they lie upon one another, or if they so move, whether with the same degree or different degrees of speed, that they communicate their motions to each other in a certain fixed manner, we shall say that those bodies are united with one another and that they all together compose one body or individual, which is distinguished from the others by this union of bodies. (E2p13le3a2d; the first emphasis added)

This means that individuals under the attribute of extension are complex bodies, composed of many other bodies - and in the end, of simplest bodies (or power quanta). ${ }^{43}$ Furthermore, the identity of an individual depends on 'a certain fixed manner' that bodies 'communicate their motions to each other.' What does Spinoza have in mind? The following lemma clarifies things:

If the parts composing an individual become greater or less, but in such a proportion that they all keep the same ratio of motion and rest to each other as before, then the individual will likewise retain its nature, as before, without any change of form. (E2p13le5; emphasis added)

Many commentators have emphasized the central importance of fixed relations (ratio) in Spinoza's theory of individuals, and rightly so. Obviously, the relation of simplest bodies - or in metaphysical terms, the relation of extended power quanta - is decisive for the identity of composite extended entities. The importance of relationality can be seen as stemming from the field character of Spinozistic metaphysics: distribution in the unified field of power is always relational, and established by the way the intensity of power is dispersed between different spatial regions. I interpret this to mean that the metaphysical description of an individual involves a fixed arrangement of interaction between power

42 Hence I agree with Lee Rice $(1971,647)$ that 'the corpora simplicissima are quite divisible.' Gueroult $(1974,161)$, too, makes essentially the same point: as parts of extension, simplest bodies must be divisible, without, however, being aggregates of parts.

43 See E2p13le7. Garrett (1994, 93-4) wonders whether simplest bodies are individuals; I think that only complex bodies are individuals, and that simplest bodies are just basic constituents of individuals. 
quanta; and that at the physical level of description this equals the relation of motion and rest between the bodies composing the individual.

Spinoza speaks of the structure (fabrica) of the human body in several places (E1app, 3p2s, 4p59s), and consequently it may be fitting to think of complex bodies as concrete kinetic structures, constituted by innumerable simple bodies in the required interactive configuration. And although Spinoza suggests in the Short Treatise (II.Pref., § 12) that the relation characterizing an individual can be expressed as mathematical ratio - such as 1 to 3 - between the sum of motion and the sum of rest of the individual's parts, I do not think that such a simple numerical proportion tells the whole story concerning kinetic structures that are spatial by nature. ${ }^{44}$

To sum up, I would like to draw a more comprehensive picture of Spinoza's theory of individuality. First, since individuals are not substances but modes of substance, there must be something that determines the way infinite attributes of the one substance are modally, and not really, divided. I agree with Matheron that individual essences are one of the indubitable starting points for Spinoza. ${ }^{45}$ Obviously, their importance lies in the fact that a finite thing's essence is the basis for individuating that thing (see E2d2), and in the context of my interpretation this means that individual essences determine the arrangements of intensity in motion without which certain intensifications filling regions in the field of power would not be distinguished as individuals. In physical terms, the relation of motion and rest between simpler bodies gives unity to an individual; we may call this, following Matheron, the formal element of individuality. ${ }^{46}$ Together, all the essences form a timeless order, produced according to the laws of God's nature. Second, there must be something actual that constitutes the individual in temporal reality, namely the concrete power quanta of which an actual complex mode is composed. Correspondingly, Matheron calls the simpler physical bodies out of which a complex body is formed the material element of individuality. ${ }^{47}$

These considerations imply that from the metaphysical point of view there are (1) eternal essences that specify certain spatial arrangements of

44 For more about relations as mathematical ratios, see Garrett, 1994, 82-7. Garrett $(1994,87)$ comes close to my position by claiming that 'ratios of motion and rest are simply fixed patterns of communicated motion and rest among parts.' See also Ablondi and Barbone, 1996, 79; Barbone, 2002, 98; Jonas, 1979 (1965), 267.

45 Matheron, 1988 (1969), 9-10, 18

46 Matheron, 1988 (1969), 39

47 Matheron, 1988 (1969), 38; for a similar view, see Deleuze, 1997 (1968), 205-6, 208. 
intensity as individuals, and (2) actual individuals, i.e. relatively stable concrete structures of power quanta that realize these arrangements in temporality. However, one can still ask how a certain arrangement of intensity can belong to a certain essence. I am willing to suggest that essences could be seen as blueprints or diagrams that pick out certain patterns of intensifications as individuals. ${ }^{48}$ This suggestion finds support from the Spinozistic theory of definition: there is a definition for each individual, a definition expressing the essence of the individual defined (TIE, § 93; E1p8s2). And not only does a definition include the cause producing the individual, but all the individual's properties can be deduced from it as well (TIE, § 96). As Matheron puts it: 'To understand a thing is to know how to produce it. ${ }^{49}$ And since definitions express essences, it is possible to think of essences as blueprints for the composition of actual individuals. However, since Spinoza does not address this topic, I prefer to leave the question open.

\section{Persistence and conatus}

Formal essences do not come and go out of existence (E2p8, 2p8c), but an individual's actual being begins and ceases at certain temporal moments. I agree with Deleuze that a mode exists actually when it possesses the extended parts that correspond to its eternal essence, ${ }^{50}$ although I consider it inexact to talk about modes as if they were entities that owned extended parts. An actual complex mode is a certain concrete structure of 'parts.' And so, an individual's temporal existence can be seen as a state of affairs where concrete power quanta are organized in the arrangement corresponding to the individual's essence.

According to the corollary of E1p24, God is the cause both of (1) things' beginning to exist, and (2) their persevering in existing. For an individual to begin to exist the right arrangement of concrete power quanta is required, and this is produced by causal effects of other finite things (E1p28). Because essences exist eternally, the temporal moment of the beginning of actual existence depends solely on the interrelation of actual power quanta. This is the way that the eternal and the temporal work together in actuality.

48 Cf. Barbone $(2002,98)$ : "This pattern can even be imagined as a "blueprint," that is, as a "construction guide" by which to arrange the necessary parts to form the individual.'

49 Matheron, 1988 (1969), 12; translation mine.

50 Deleuze, 1997 (1968), 202; see also Deleuze, 1988 (1981), 76. 
But what about the persistence of existence? This concerns the problem of individual identity through time: how does Spinoza explain the continuity of individual existence? To begin with, it is very interesting to observe that according to Spinoza, it does not matter which particular parts comprise a physical individual (for example a human body) at a given time:

If, of a body, or of an individual, which is composed of a number of bodies, some are removed, and at the same time as many others of the same nature take their place, the individual will retain its nature, as before, without any change of its form. (E2p13le4)

As is well known, a great portion of any human body is renewed several times during its lifetime. Interpreted from the viewpoint of power, a human body is constituted by an extremely complex arrangement of power whose quanta or parts must remain in a certain fixed relation for the body's temporal existence to continue. So, when a mode moves or its parts change (E2p13le4-le7), this requires extremely rapid re-organization in the field of power - the regions the mode fills often change completely. To illustrate this, we can consider for example a tennis ball moving swiftly across a tennis court. The ball (i.e. a determinate physical-kinetic structure) is, metaphysically speaking, a spatial pattern of power quanta. And from this it follows that as the ball moves the quanta that constitute it occupy continually new regions of space, but in such a fashion that despite this continual spatial alteration, the power quanta are maintained in the arrangement corresponding to the essence of the tennis ball. In other words, the unified power field alters so that subsequent regions are filled by the pattern of intensification physically conceptualized as the ball. Thus, the infinite spatio-temporal field of power is in a state of flux, ceaselessly re-ordered, while power as a whole stays the same. ${ }^{51}$

If the power quanta that constitute a human being, for instance, can frequently move and change, it must be asked how it is possible that they nevertheless remain in a particular interrelation or arrangement. Why, for example, does a highly complex human body continue its existence for a prolonged time and not simply disintegrate? In order to answer this question it is necessary to connect the considerations of the

51 In the famous E2p13le7s Spinoza considers the whole of nature as 'one individual, whose parts, that is, all bodies, vary in infinite ways, without any change of the whole individual.' I interpret this to mean that extended nature as infinite power does not alter, although as it is distributed through the eternal order of essences the temporal reality varies without end. 
Physical Digression to Spinoza's famous doctrine of conatus, presented in the third part of the Ethics: individuals persevere in existence due to the eternal essence as actual conatus (E3p6-3p7), or striving to persevere in being. In other words, a thing's essence in temporal reality has conatus nature. The essential conatus power, the basic striving to persevere in being, explains why the pattern of power that forms the individual is held together from one moment to another-even if in the field of power its location (and in some respects its character) would alter. $^{52}$ This stability of arrangement equals the fixed relation of motion and rest Spinoza discusses in the Physical Digression.

Garrett is right in holding that Spinoza's theory of physical individuality provides specific content to the doctrine of self-preservation. My position is close to Garrett's also in that we both hold, like many other scholars, the maintenance of the continuing ratio or pattern of motion and rest to be the proper activity of the individual that has a certain nature. ${ }^{53}$ Without the conatus character of its essence an individual body would not have any continuity of actual existence, but would be immediately disintegrated - just as physical motion according to the principle of inertia would not be possible without the conatus power behind it. Hence, the conatus doctrine is one of the most profound aspects of Spinozistic dynamism and naturalism, in which human beings also are necessar-

52 As an anonymous referee of this journal pointed out, since any complex thing's simpler parts are powers to cause effects, the question concerning persistence of such individuals can be stated as, 'why do these powers remain bundled?' And it seems superficial just to reply that there is a striving power to maintain the individual's existence, for then it may be asked, what keeps that power bundled with the others. It is unclear whether Spinoza can give a satisfactory answer to this problem, but his view is obviously that conatus is not so much one power among others as the character or direction of things' power: in temporal reality of resistances and hindrances, any entity's power is manifested as striving to keep the complex thing's essence instantiated, which means that Spinozistic things' power is exerted against destructive external causes. On what grounds can Spinoza claim that temporal things' power is such striving is another matter and depends on how one interprets the proof of the conatus proposition (E3p6d), but that demonstration seems to turn on the idea that a proper notion of power implies that in case of opposition, a thing endowed with power truly resists opposing factors and does not simply cease its causal activities whenever facing obstacles (for more on this, see Viljanen, forthcoming). However, as complex things are formed out of simpler things, this leaves open the question of how should the relationship between the striving of a complex individual and the strivings of its simpler parts be conceived; in any case, Spinoza seems to think that a complex thing's essence, together with the thing's striving power, has a particular nature not simply derivable from the simpler entities' essences or powers. Related to this, see Ep32 and below. 
ily part of nature. Moreover, Spinoza introduces the notion of power in the admittedly highly abstract first part of the Ethics, but later on he links it up with our experience, suggesting that power is something we are familiar with: desire, one of the three basic emotions, is a form of conatus, i.e., expression of the one and the same God's power operating everywhere (E3p6d) of which we are aware (E3p9s). Thus as our desires involve consciousness of power, we become acquainted with God's power through them. ${ }^{54}$

We can take a look at the famous letter including the analogy of 'a tiny worm living in the blood' in order to further illustrate the role of conatus. There Spinoza writes that 'all the parts [of the blood] are controlled by the overall nature of the blood and compelled to mutual adaptation as the overall nature of the blood requires, so as to agree with one another in a definite way' (Ep32; emphases added). I take this to mean that blood's nature has conatus character that forces simpler parts to the relation corresponding to blood's essence, making blood a harmonious (i.e. consistent) individual capable of persevering in being. No doubt, this 'controlling' and 'agreement' requires constant activity that distinguishes an individual from a mere aggregate of finite things. ${ }^{55}$

A timeless individual essence determines what kind of arrangement of power conatus must maintain in order to constitute the individual; and since intensifications of power are always in motion, this arrangement equals the stable relation of motion and rest. As Deleuze comments, 'mechanism does not exclude the idea of a nature or essence of each body, but rather requires it, as the sufficient reason for ... a given proportion of movement and rest. ${ }^{, 56} \mathrm{I}$ believe that this is not too far from Gueroult's position: although he opposes combining conatus doctrine with the Physical Digression, he does end up stressing the 'metaphysic of essences' underlying Spinozistic physics. ${ }^{57}$ Gueroult also rightly proclaims Spinoza as a forerunner of Leibniz in the sense that also for Spinoza the purely mechanistic and relational physics is subordinate to the dynamic internal powers of individuals. ${ }^{58}$

54 I am grateful to Olli Koistinen for helping me in developing this point.

55 Many commentators have drawn attention to this; see e.g. Barbone, 2002, 96-7, 100; Rice, 1971, 648, 654.

56 Deleuze, 1997 (1968), 228

57 Gueroult, 1974, 187-8. Insofar as Gueroult's point in keeping conatus apart from physics is simply that conatus as a metaphysical principle cannot be an element of physical reality, I have no objection to it.

58 Gueroult, 1974, 187-9. Seen from this perspective, Spinoza's physics presented in the Digression is rather a carefully thought-out theory where 'mechanistic phys- 
If we keep in mind the conatus character of our essential power (E3p6, $3 p 7)$ - the striving to maintain a certain pattern of power quanta - together with the thesis that an individual's actualization is caused solely by other modes (not by the individual's conatus) (E1p24, 1p28), the emerging picture of modes, and thus also of human beings, is highly compelling. Because the existence of any human being is produced by the necessity of causal laws, without any kind of teleology (E1p17, 1app, 4pref), substantial power does not consciously strive to form patterns that would correspond to certain individuals' eternal essences. But when an individual's eternal essence is actualized in duration by other modes, substantial power as conatus in a sense 'grabs hold of' the formation that corresponds to the individual's eternal essence. This is the moment when, for example, a human being is born and the striving to maintain her existence begins. The essential conatus power explains why the pattern of power that constitutes our body is renewed or regenerated constantly from one moment to another. However, our persevering conatus power is limited, and there comes a time when it can no more oppose the decomposing external powers, and the structure of our body is no longer renewed. As a result, no region in the power field corresponds to our essence - an event more familiarly called death (see E4p3, 4p39s). Of course, power that used to be arranged in a manner called 'a human being' does not disappear; it is simply re-distributed anew.

\section{Conclusion}

I have argued above that Bennett's field metaphysical interpretation is basically right and that it can be fruitfully combined with a dynamistic view of Spinozistic substance. Contrary to what has been sometimes claimed, it is by no means out of place or strange to approach Spinoza's thought this way: if we start from the idea of some basic stuff - be it, for instance, mass, temperature, electrical strength, or power - that is distributed continuously and variably throughout the unique and unified extension, we arrive at a conception of spatial reality as a field. ${ }^{59}$ With respect to Spinoza, what emerges from this point of view are finite

ics and rigorous metaphysics reciprocally imply and interpenetrate one another' (Lecrivain, 1986, 58) than a mere 'placeholder for a detailed biological theory that still lay in the future' (Bennett, 1984, 107). Cf. also Ablondi and Barbone, 1996, 83.

59 Here I am leaning on Mark Wilson's $(1998,668)$ formulation: 'A physical quantity (such as mass, temperature or electrical strength) appears as a field if it is distributed continuously and variably throughout a region.' 
things as modes that can be described as formations of intensity in the unified field of power. The rudimentary physical entities, simplest bodies, result from constantly moving quanta of power that strive to fill their regions of space. These basic constituents of physical reality form complex entities whose metaphysical essence not only individuates certain formations of dynamic intensifications as individuals but also strives to maintain their temporal existence. As long as our essential conatus can battle the disintegrating effects of external causes, a certain region of space remains identifiable as our body; further, the character of our existence is determined by the relation between our power and the other powers in the field. And so, it is only fitting that Spinoza's ethical project is inherently dynamistic, aiming to provide us with strategies of reason that help our essential power be realized as freely as possible in this field of constant contest. ${ }^{60}$

Received: May 2005

Revised: November 2005, July 2006

\section{References}

Ablondi, F., and Barbone, S. 1996. 'Individual Identity in Descartes and Spinoza.' Studia Spinozana 10: 69-91.

Barbone, S. 2002. 'What Counts as an Individual for Spinoza?' In Spinoza. Metaphysical Themes, O. Koistinen and J. Biro, eds. Oxford: Oxford University Press.

Bennett, J. 1984. A Study of Spinoza's Ethics. Cambridge: Cambridge University Press.

1991. 'Spinoza's Monism: A Reply to Curley.' In God and Nature: Spinoza's Metaphysics, Y. Yovel, ed. Leiden, New York, København, and Köln: E.J. Brill.

1996. 'Spinoza's Metaphysics.' In The Cambridge Companion to Spinoza, D. Garrett, ed. Cambridge: Cambridge University Press.

2001. Learning from Six Philosophers. Descartes, Spinoza, Leibniz, Locke, Berkeley, Hume. Volume 1. Oxford: Clarendon Press.

Carriero, J. 1995. 'On the Relationship between Mode and Substance in Spinoza's Metaphysics.' Journal of the History of Philosophy 33: 245-73.

60 I am deeply grateful to Olli Koistinen, Juhani Pietarinen, Arto Repo, and Andreas Schmidt for their many helpful suggestions and stimulating discussions concerning this paper. I would also like to thank the referees for their comments and criticisms. Finally, I would like to acknowledge that the work on this paper was supported by the Turku University Foundation. 
Curley, E. 1991. 'On Bennett's Interpretation of Spinoza's Monism.' In God and Nature: Spinoza's Metaphysics, Y. Yovel, ed. Leiden, New York, København, and Köln: E.J. Brill.

Deleuze, G. 1988. Spinoza: Practical Philosophy (Spinoza: Philosophie pratique 1981). R. Hurley, trans. San Francisco: City Lights Books.

1997. Expressionism in Philosophy: Spinoza (Spinoza et le problème de l'expression 1968). M. Joughin, trans. New York: Zone Books.

Della Rocca, M. 2003. 'The Power of an Idea: Spinoza's Critique of Pure Will.' Nous 37: 200-31.

Esfeld, M. 2002. Holismus in der Philosophie des Geistes und in der Philosophie der Physik. Frankfurt am Main: Suhrkamp.

Garber, D. 1996. 'Descartes and Spinoza on Persistence and Conatus.' Studia Spinozana 10: $43-67$.

Garrett, D. 1994. 'Spinoza's Theory of Metaphysical Individuation.' In Individuation and Identity in Early Modern Philosophy. Descartes to Kant, K.F. Barber and J.J.E. Garcia, eds. Albany: State University of New York Press.

Gueroult, M. 1968. Spinoza I. Dieu. Hildesheim: Georg Olms Verlagsbuchhandlung. . 1974. Spinoza II. L'Âme. Hildesheim and New York: Georg Olms Verlagsbuchhandlung.

Harris, E.E. 1973. Salvation from Despair. A Reappraisal of Spinoza's Philosophy. The Hague: Martinus Nijhoff.

Jonas, H. 1979. 'Spinoza and the Theory of Organism (1965).' In Spinoza. A Collection of Critical Essays, M. Grene, ed. Notre Dame: University of Notre Dame Press.

Kant, I. 1992. 'Physical Monadology (Monadologiam physicam, 1756).' In Immanuel Kant, Theoretical Philosophy, 1755-1770. D. Walford, trans. and ed. Cambridge: Cambridge University Press.

Koistinen, O. 1991. On the Metaphysics of Spinoza's Ethics. Turku: University of Turku.

Lachterman, D.R. 1978. 'The Physics of Spinoza's Ethics.' In Spinoza: New Perspectives, R.W. Shahan and J.I. Biro, eds. Norman: University of Oklahoma Press.

Lecrivain, A. 1986. 'Spinoza and Cartesian Mechanics.' In Spinoza and the Sciences, M. Grene and D. Nails, eds. Dordrecht: D. Reidel Publishing Company.

Matheron, A. 1988. Individu et communauté chez Spinoza (1969). Paris: Les Éditions de Minuit.

Pietarinen, J. 2000a. 'Spinoza: hyve on valtaa.' In Mitä on valta? J. Räikkä and M. Wennberg, eds. Kuopio: Unipress.

2000b. 'The Rationality of Desires in Spinoza's Ethics.' In Rationality and Irrationality (Contributions of the Austrian Ludwig Wittgenstein Society 8). B. Brogaard, ed. Kirchberg: Austrian L. Wittgenstein Society.

2003. 'Spinoza on Causal Explanation of Action.' In Realism in Action, M. Sintonen, P. Ylikoski, and K. Miller, eds. Dordrecht, Boston, and London: Kluwer Academic Publishers. 
Rice, L.C. 1971. 'Spinoza on Individuation.' The Monist 55: 640-59.

Rohs, P. 1996. Feld - Zeit - Ich: Entwurf einer feldtheoretischen Transzendentalphilosophie. Frankfurt am Main: Vittorio Klostermann.

Sachs, M. 1976. 'Maimonides, Spinoza, and the Field Concept in Physics.' Journal of the History of Ideas 37: 125-31.

Spinoza, B. 1985. Treatise on the Emendation of the Intellect (Tractatus de intellectus emendatione). In The Collected Works of Spinoza Volume 1. E. Curley, ed. and trans. Princeton: Princeton University Press. $=$ TEI

1985. Short Treatise on God, Man and His Well-Being (Korte Verhandeling). In The Collected Works of Spinoza Volume 1. E. Curley, ed. and trans. Princeton: Princeton University Press. $=$ KV.

1985. Descartes' 'Principles of Philosophy' (Principia Philosophiæ Cartesianæ). In The Collected Works of Spinoza Volume 1. E. Curley, ed. and trans. Princeton: Princeton University Press. $=$ DPP.

1985. The Ethics (Ethica ordine geometrico demonstrata). In The Collected Works of Spinoza Volume 1. E. Curley, ed. and trans. Princeton: Princeton University Press. = E.

1995. The Letters. S. Shirley, trans. Indianapolis and Cambridge: Hackett Publishing Company. $=$ Ep.

Van Zandt, J.D. 1986. 'Res extensa and the Space-Time Continuum.' In Spinoza and the Sciences. M. Grene and D. Nails, eds. Dordrecht: D. Reidel Publishing Company.

Viljanen, V. forthcoming. 'On the Derivation and Meaning of Spinoza's Conatus Doctrine.' In Oxford Studies in Early Modern Philosophy, Volume IV. D. Garber and S. Nadler, eds. Oxford: Oxford University Press.

von Dunin Borkowski, S. 1933. 'Die Physik Spinozas.' Septimana Spinozana: 85-101.

Wilson, M. 1998. 'Field Theory, Classical.' In Routledge Encyclopedia of Philosophy Volume 3. E. Craig, ed. London and New York: Routledge.

Wilson, M.D. 1996. 'Spinoza's Theory of Knowledge.' In The Cambridge Companion to Spinoza. D. Garrett, ed. Cambridge: Cambridge University Press.

Wolf, A. 1974. 'Spinoza's Conception of the Attributes of Substance (1927).' In Studies in Spinoza. Critical and Interpretive Essays. S.P. Kashap, ed. Berkeley and Los Angeles: University of California Press.

Wolfson, H.A. 1961. The Philosophy of Spinoza. Two Volumes in One (1934). Cleveland and New York: Meridian Books. 